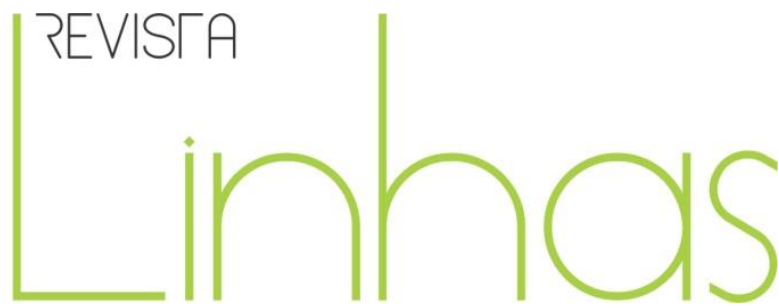

\title{
Literatura, saber e sabor: o alimento na literatura
}

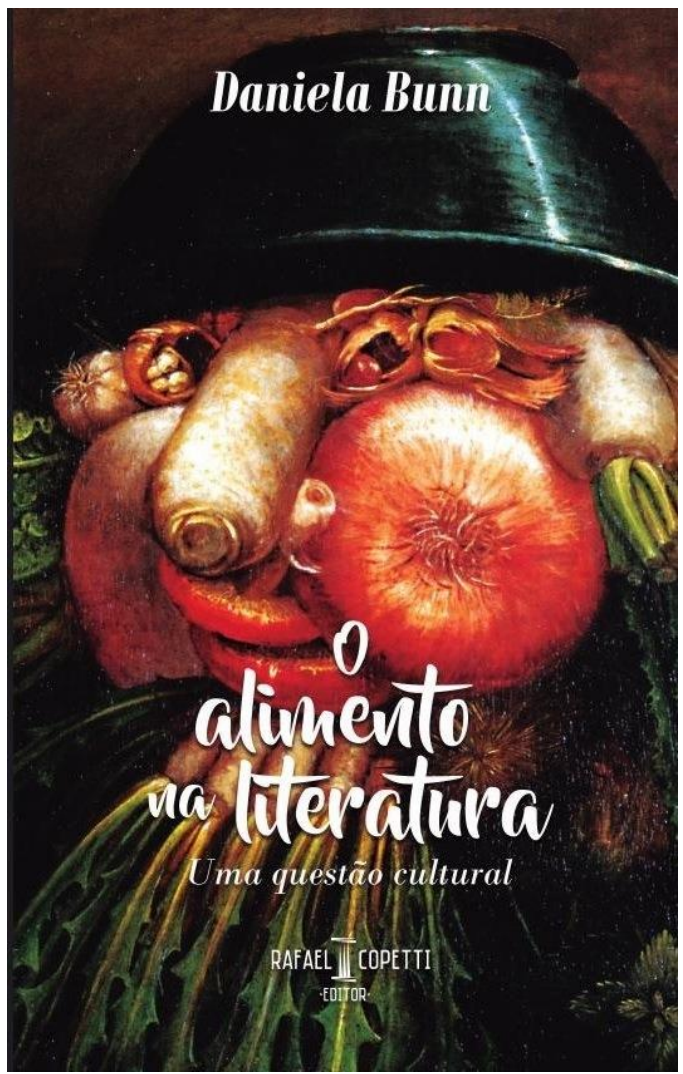

BUNN, Daniela. $O$ alimento na literatura: uma questão cultural. São Paulo: Rafael Copetti Editor, 2016.

\section{Diana Navas}

Pontifícia Universidade Católica de São Paulo - PUC/SP - Brasil

diana.navas@hotmail.com

\section{Para citar esta resenha:}

Diana Navas. Resenha do livro "O alimento na literatura: uma questão cultural”. Revista Linhas.

Florianópolis, v. 18, n. 37, p. 308-312, maio/ago. 2017.

\section{DOI: $10.5965 / 1984723818372017308$}

http://dx.doi.org/10.5965/1984723818372017308 
Professora nos ensinos fundamental, médio e superior, Daniela Bunn é doutora em Literatura pela Universidade Federal de Santa Catarina e muito tem se dedicado à literatura infantil, seja por meio de sua atuação profissional - visto circular pelas diversas esferas educacionais -, seja por sua produção de artigos científicos relacionados com a literatura e sua fundamental importância no ambiente escolar. Sua contribuição à literatura destinada aos pequenos leitores torna-se ainda mais significativa quando consideramos sua atuação como escritora e tradutora. Até o momento, Daniela traduziu treze livros de Literatura Infantil, alguns dos quais compõem a Coleção Pequenas Grandes Histórias, e que foram selecionados para o Programa Nacional Biblioteca na Escola (PNBE), pelo Ministério da Educação, em 2012, ou para o projeto Livros da Sala de Aula, da Secretária da Educação de São Paulo no mesmo ano.

O mais recente livro de Daniela Bunn (2016), O alimento na literatura: uma questão cultural, vem se somar às produções anteriores, e com elas fortemente dialogar. Com um bonito e significativo trabalho editorial, a obra organiza-se literalmente como um cardápio, por meio do qual se oferece ao público leitor uma completa refeição - que vai do antepasto à sobremesa. Por meio dessa deliciosa e nutritiva refeição-leitura, a autora discute a presença do alimento na literatura ao mesmo tempo em que nos convida a pensar a literatura como alimento, oferecendo-nos um percurso histórico da fome e do desejo de comer, da devoração cultural e de uma educação alimentar e literária. Para nos acompanhar nesse percurso, a autora sugere-nos, ainda, em cada etapa de nossa "refeição", uma trilha sonora e excertos de textos literários que contribuem para o deleite de suas reflexões teórico-críticas.

Como Antepasto, Daniela Brunn apresenta-nos as inquietações que geraram a pesquisa que se efetiva neste livro. Dentre as principais indagações que norteiam suas reflexões estão: como o alimento é representado nas histórias infantis? O alimento desempenha ou não um papel significativo para o imaginário infantil? O alimento presente nas histórias pode ou não contribuir para o trabalho com a literatura em sala de aula? Como o discurso crítico se vale de metáforas e imagens relacionadas ao campo alimentar? No intento de responder a esses questionamentos, inicia-se o servir de pratos 
repletos de instigantes reflexões que nos auxiliam a pensar a presença do alimento na literatura e a literatura como alimento.

Em Saladas Históricas, primeiro capítulo da obra, Daniela nos apresenta ideias e metáforas recorrentes na crítica literária e educacional relacionadas ao alimento ao longo do tempo, baseando-se, para isso, em pesquisas realizadas acerca da história da alimentação. Mais do que apresentar um rico percurso histórico, evidenciando-nos de que forma o alimento sempre esteve presente na literatura - da dietética à gastronomia, do banquete à fome, do livro de receitas ao consumismo exacerbado - e como se evidencia no discurso crítico, por meio do que denomina de "metáfora alimentar", a autora convida-nos a refletir criticamente sobre a produção editorial destinada às crianças na contemporaneidade, de forma a distinguirmos, neste mercado, o que temos de atrativo e de nutritivo.

Neste viés, além de nos servir variados exemplos acerca da presença do alimento nas mais diferentes histórias literárias, Daniela discute o papel significativo do professor na escolha da alimentação que será servida aos iniciantes leitores, atentando-nos para duas competências desse mediador: a compreensão da importância dos contos clássicos como lastros para a vida adulta e leitora do indivíduo; e a necessidade de atualizar constantemente seu repertório, a fim de atender às expectativas dos leitores de nosso tempo. Considerando que o gosto alimentar é cultural e, portanto, pode e deve ser constantemente melhorado, cabe ao professor, de acordo com a pesquisadora, ajudar o aluno a saborear, auxiliando-o, por meio de uma reeducação alimentar, a descobrir os mais intensos sabores dos textos literários.

Em Carnes Selecionadas, segundo prato-capítulo, a autora revela-nos diversas opções para saborearmos a imagem alimentar, iniciando pela apresentação dos critérios norteadores da escolha do corpus de sua pesquisa. Neste capítulo, na medida em que traça brevemente a trajetória da literatura infantil no Brasil, Daniela apresenta-nos e discute o tema da fome e do desejo de comer presentes em alguns contos clássicos, como é o caso de Pollicino (O pequeno Polegar), João e Maria ou, ainda, de O Gato de Botas. A metamorfose por meio da boca - seja pela ingestão de algum alimento ou do 
beijo - é também abordada e exemplificada por meio de histórias como a A princesa e o sapo ou do livro Sapomorfose ou o príncipe que coaxava.

Além de uma produtiva apresentação das histórias infantis e suas ilustrações, é válido ressaltar neste capítulo a discussão empreendida pela autora acerca da importância de bem selecionar os ingredientes-histórias que serão servidos às crianças. Considerando a ampla e crescente produção de livros a elas destinados, Daniela Bunn reforça, novamente, a importância de critérios concernentes ao texto, à ilustração e aos aspectos gráficos no momento da escolha do livro pelo mediador, de forma a oferecer um alimento realmente nutritivo - e não meramente atrativo - ao leitor em formação. Ao professor cabe, segundo a pesquisadora, não apenas conhecer o repertório que o aluno possui, mas ampliá-lo e contribuir para aguçar sua criatividade para o alargamento deste repertório, nutrindo o imaginário da criança com histórias tradicionais e contemporâneas, permitindo a ela que se alimente de um bem cultural do qual é herdeira.

O prato principal de nossa leitura-refeição é oferecido em Festival de Massas, capítulo no qual a autora apresenta-nos, de forma bastante prazerosa, a releitura de algumas histórias clássicas, destacando, dentre elas, a história de Chapeuzinho Vermelho. Demonstrando amplo repertório, Daniela convida-nos, neste momento, a conhecermos diferentes versões da história de Chapeuzinho - das mais clássicas às contemporâneas nas quais, considerando o texto e as ilustrações, exibe-nos as mais variadas representações da cesta levada à avó neste conto. A partir desta exibição, a autora convida-nos a perceber como, ainda que haja deslocamentos de vários elementos na história, o alimento permanece nela presente, sendo atualizado e recebendo o "sabor do local”. Atenta-nos, também, para como a ressignificação dos contos é capaz de mantê-los vivos e encantar os jovens e velhos leitores.

Ainda neste capítulo, a autora leva-nos a conhecer categorias pertinentes à imagem alimentar, categorias essas que vão do estético ao educativo, ressaltando alguns textos que concernem ao corpo, ao apetite, à gula, bem como ao que denomina nos quesitos de cardápios poéticos e pomar de sabores. A apresentação dessas categorias, mais do que exibir o amplo repertório de leituras de literatura infantil da autora - tão 
generosamente servido aos leitores de sua obra - permite-nos reconhecer como comer e ler são atividades tão análogas.

Como sobremesa, Daniela nos oferece uma conversa que, no entanto, não se finda, visto estarmos diante de uma obra capaz de despertar inúmeras reflexões e propostas de trabalho com o literário em sala de aula. Uma obra que, justamente por não se apresentar nos tradicionais moldes científicos, visto oferecer-se como um banquete repleto de música e poesia - apesar de seu rigor acadêmico - suscita o nosso estranhamento e convida-nos à releitura e ao deleite.

O livro O alimento na literatura - uma questão cultural (2016), de Daniela Bunn, é, indubitavelmente, uma produção significativa para compor o acervo daqueles que refletem sobre a produção literária destinada às crianças, revelando-se como um banquete destinado aos pesquisadores e professores dispostos a saborearem a literatura infantil sempre em busca de novos sabores e saberes.

Recebido em: 20/03/2017 Aprovado em: 28/03/2017

Universidade do Estado de Santa Catarina - UDESC Programa de Pós-Graduação em Educação - PPGE Revista Linhas Volume 18 - Número 37 - Ano 2017 revistalinhas@gmail.com 